\title{
Experimental Investigation of a Solid Propellant Ducted Rocket with a Chin Type Inlet*
}

\author{
Binbin CHeN, ${ }^{1)}$ Zhixun XIA,${ }^{1 \dagger \dagger}$ Liya HuAnG, ${ }^{1)}$ Likun MA, ${ }^{1)}$ and Gang LONG ${ }^{2)}$ \\ ${ }^{1)}$ College of Aerospace Science and Engineering, National University of Defense Technology, Changsha, Hunan 410073, China \\ ${ }^{2)} X i$ 'an Modern Control Technology Research Institute, Xi'an, Shanxi 710065, China
}

In this study we report an experimental research on the characteristics of combustion chamber in a solid propellant ducted rocket (SPDR) with a chin type inlet. Two kinds of propellants are tested, including boron-based solid propellant and hydrocarbon solid propellant. A new configuration of the SPDR with swirling flow is proposed. Effects on combustion characteristic of swirling flow, chamber length, propellant type and equivalence ratio are conducted. Results show that combustion efficiency based on temperature rise of the SPDR with swirling flow can reach 95\%, which is 7\% higher than the one without swirling flow. Furthermore, the swirler used in this study offers a significant effect on thermal protection. The combustion efficiency of hydrocarbon fuel-rich propellant is lower than that of boron-based fuel-rich propellant, and the SPDR using hydrocarbon propellant suffers from an ignition delay problem. When equivalence ratio decreases, combustion efficiency of the SPDR without swirling flow remains the same, whereas combustion efficiency of the SPDR with swirling flow increases first and then decreases.

Key Words: Combustion Characteristic, Solid Propellant Ducted Rocket, Experimental Investigation, Swirling Flow, Propellant Type

\section{Nomenclature}

$a_{0}$ : total pressure recovery coefficient of the convergent part of nozzle

$a$ : coefficient of rate

$A_{\mathrm{c}}$ : area of the chamber exit

$A_{\mathrm{g}}$ : area of the gas generator throat

$A_{\mathrm{p}}$ : combustion area of the propellant

$A_{\mathrm{t}}$ : area of the nozzle throat

$C^{*}$ : characteristic velocity of gas generator

$D$ : diameter

$F_{\mathrm{g}}$ : connected-pipe test thrust

I: specific impulse

Ma: Mach number

$\dot{m}_{\mathrm{a}}$ : average mass flow rate of air

$\dot{m}_{\mathrm{g}}$ : gas flow rates

$m_{\text {int }}$ : initial mass of propellant

$m_{\mathrm{r}}$ : remaining mass of propellant

$n$ : pressure index of the propellant

$P_{\mathrm{c}}^{*}$ : total pressure of the chamber

$P_{\mathrm{g}}$ : pressure at the ground

$P_{\mathrm{h}}$ : pressure at the flight altitude

$q(M a)$ : flow function

$r$ : radius location

$R_{1}$ : outer radius of swirler

$R_{2}$ : radius of chamber

$S$ : swirl number

$t$ : working time of experiments

$T$ : temperature

(C) 2019 The Japan Society for Aeronautical and Space Sciences *Received 17 August 2018; final revision received 24 January 2019; accepted for publication 8 February 2019.

†Corresponding author, zxxia@nudt.edu.cn
$T_{\mathrm{c}}$ : temperature of chamber

$u$ : axial velocity

$w$ : tangential velocity

$\rho_{\mathrm{p}}$ : ensity of the propellant

$\Theta$ : degree

$\Delta t$ : operation time

$\eta_{\mathrm{T}}$ : combustion efficiency based on temperature rise

$\eta_{\mathrm{I}}$ : specific impulse efficiency

Subscripts

c: chamber

exp: experiment

g: gas/gas generator

th: heory

$\infty$ : in infinite distance

Acronyms

ER: equivalence ratio

SPDR: solid propellant ducted rocket

\section{Introduction}

The solid propellant ducted rocket (SPDR), also known as ducted rocket or integral rocket ramjet, is a supersonic flight propulsion, it takes the exhaust from a solid propellant gas generator, mixes it with air and burns it to produce thrust. It is a concept that combining solid propellant rockets with airbreathing engines, leading to several advantages over solid propellant rockets including longer flight capability, higher speed and throttleability, and has received great attention in recent years. ${ }^{1-5)}$ Combustion performance is a critical issue in the efficient operation of SPDRs ${ }^{1)}$ because it directly affects mission performance. In the past few decades, many studies focused on the combustion performance of SPDRs, accounting for propellant type, ${ }^{6-9)}$ gas injection device, ${ }^{7,10-13)}$ 
inlet type ${ }^{10,14-17)}$ and chamber configuration. ${ }^{18-22)}$

However, most of these studies are forced on SPDRs with four inlets or two inlets, combustion characteristics of SPDRs with chin inlets are not found in open literature. The chin type inlet could achieve high performance over a wide range of Mach numbers, altitudes and angles of attack, ${ }^{23)}$ but it suffer from bad mixing and combustion performance. Thus, combustion characteristics of SPDRs with a chin type inlet should be investigated to improve the combustion performance.

In current study, combustion characteristics of a SPDR with a chin type inlet were investigated experimentally, a new swirler was designed and used to achieve high combustion performance. The influences of swirling flow, chamber length, propellant type and equivalence ratio (ER) were analyzed. The connected-pipe apparatus, the test SPDR and data processing method are presented in Section 2. In Section 3, the test results are provided and the influences of structural parameters, propellant type and ER on the combustion characteristics of the SPDR are discussed. Thereafter, conclusions are summarized.

\section{Experimental Apparatus and Data Acquisition}

\subsection{Experimental apparatus}

As shown in Fig. 1, the connected-pipe test facility used in this study comprises a vitiated air heater, a thrust stand and a test ducted rocket. Ethanol, oxygen and air are used to generate hot air in the vitiated air heater, thereby simulating the stagnation parameters at a certain flight condition. The parameters include a total temperature of $625 \mathrm{~K}$, and a stagnation pressure of $0.97 \mathrm{MPa}$, which represents the flight condition at an altitude of $10 \mathrm{~km}$, and a Mach number of 3.0. The stagnation pressure is maintained by the mass flow rate of hot air and the nozzle area at the exit of air heater.

\subsection{Test SPDR}

The test SPDR includes a chin type inlet, a gas generator, a ducted chamber and a nozzle. The chin inlet is simplified as a rectangular inlet with a small inlet angle for the laboratoryscale tests. The gas generator is a small rocket. The nozzle contains a convergent part with 45 degrees, a columniform part and an expand part of about 15 degrees. The nozzle throat is varied to keep chamber pressure.

Two types of propellant are tested in this study: boronbased fuel-rich propellant and hydrocarbon fuel-rich propellant. The boron-based propellant mainly contains 33\% ammonium perchlorate (AP), 29\% hydroxyl-terminated polybutadiene (HTPB), 33\% boron (B) and 5\% magnesium. The

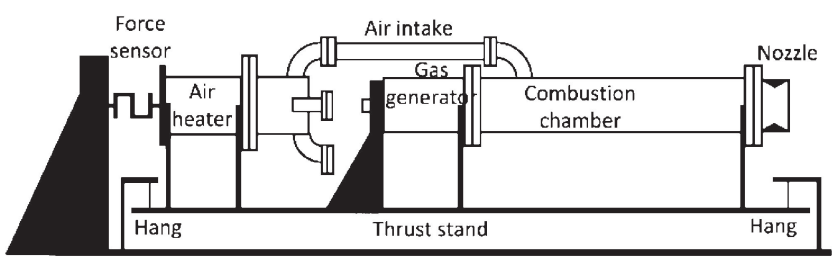

Fig. 1. Schematic of experimental apparatus. hydrocarbon propellant is composed of 35\% AP, 25\% HTPB and $40 \% \mathrm{C}_{11} \mathrm{H}_{14}$.

According to the burn rate formula of propellant (formula (3)), we can find that the mass flow rate of primary fuel-rich gas can be varied by changing the pressure of gas generator, the pressure of gas generator is controlled by the area of the gas generator throat. Therefore, the mass flow rate of primary fuel-rich gas can be varied by changing the area of the gas generator throat. The generator throat and the nozzle throat are made by graphite, and will be replaced during every test.

Schematic of the test ducted chamber is shown in Fig. 2, the detailed geometric specifications are summarised in Table 1. Swirling flow could improve the mixing and combustion performance of SPDRs, ${ }^{24)}$ thus, two types of chamber with a chin inlet are tested in this study: a chamber without swirler and another with a swirler. The swirler (Fig. 3) is very simple, it has a central cylindrical inner wall with a $50 \mathrm{~mm}$ diameter and a cylindrical-divergent outer wall. It is designed for installation in the dome region, the primary fuel rich gas decelerates to subsonic after flowing through inner wall of the swirler, the ducted air flows to sidewall of the chamber and generates a pair of reverse eddies through outer wall of the swirler. The Streamline of the SPDR with a swirler is shown in Fig. 4.

The swirl number can be physically defined as the ratio of axial fluxes of swirl and linear momentum divided by a characteristic radius. ${ }^{22)}$ In the study, the swirl number is calculated at the exit of swirler and is 0.17 .
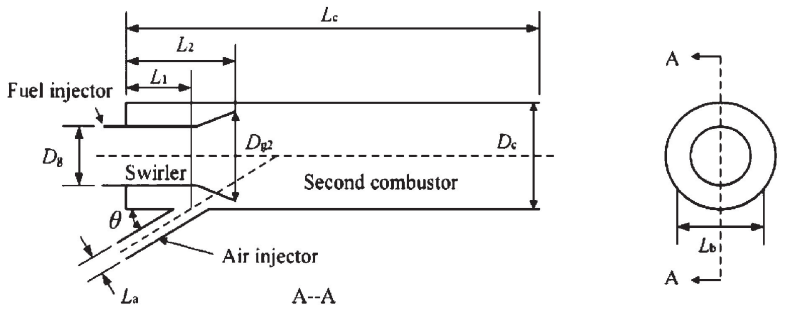

Fig. 2. Schematic of an SPDR chamber with a swirler.

Table 1. Geometries of the chamber.

\begin{tabular}{clll}
\hline Parameter & Size & Parameter & Size \\
\hline$L_{\mathrm{c}}(\mathrm{mm})$ & $730 / 580$ & $D_{\mathrm{c}}(\mathrm{mm})$ & 100 \\
$L_{1}(\mathrm{~mm})$ & 53.4 & $D_{\mathrm{g}}(\mathrm{mm})$ & 76 \\
$L_{2}(\mathrm{~mm})$ & 132 & $D_{\mathrm{g} 2}(\mathrm{~mm})$ & 88 \\
$L_{\mathrm{a}}(\mathrm{mm})$ & 25 & $\Theta($ degrees $)$ & 30 \\
$L_{\mathrm{b}}(\mathrm{mm})$ & 75 & & \\
\hline
\end{tabular}

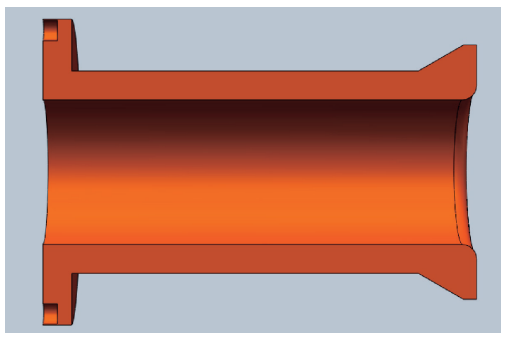

Fig. 3. Schematic of the swirler. 


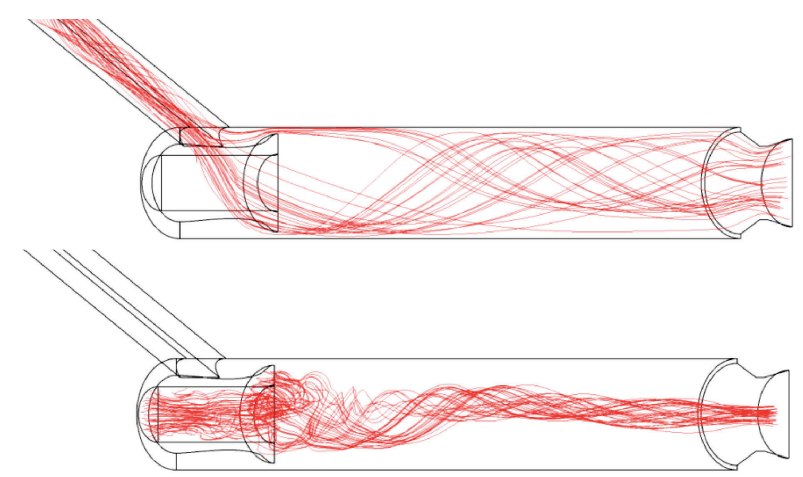

Fig. 4. Streamline of the SPDR with a swirler.

$$
S=\int_{R_{1}}^{R_{2}} u w r^{2} d r /\left(R_{2} \int_{R_{1}}^{R_{2}} u^{2} r d r\right)
$$

\subsection{Data acquisition and processing method}

Three types of parameters are recorded during the experiments, namely, mass flow rate, pressure and thrust. The mass flow rates of liquid and gas are measured by turbo flow meters. The accuracy of the flow meters is about $\pm 0.2 \%$ of the full scale. Pressure is measured by piezoresistive pressure transducers. Two types of piezoresistive pressure transducers are used. High pressures in the vitiated air heater and gas generator are measured by piezoresistive pressure transducers in the range of $0-10 \mathrm{MPa}$. Low pressure in the ducted chamber is measured by a piezoresistive pressure transducer in the range of $0-2 \mathrm{MPa}$. The accuracies of both types of transducers equate to approximately $\pm 0.2 \%$. The thrust force is measured by a force sensor (model BLR-2) with an accuracy of about $\pm 50 \mathrm{~N}$. All data from the sensors transmit to a PXI measurement system through high-speed Ethernet. The PXI system is connected to the control system to diagnose real-time status.

After the experiments, the data should be processed to evaluate combustion performance of the test SPDR. During the data processing, operation time of the ducted rocket should be defined first to ensure the mass flow rates of gas. The combustion efficiency and specific impulse efficiency are then calculated with the geometric parameters and other measured data.

Three methods are used to obtain gas flow rates. The first method involves the average mass flow rates of gas flow, which is defined as the combustion mass of propellant divided by the operation time of the ducted rocket. Combustion mass is defined as the initial mass of propellant minus the remaining mass:

$$
\dot{m}_{\mathrm{g}}=\left(m_{\mathrm{int}}-m_{\mathrm{r}}\right) / \Delta t
$$

The second method involves the burn rate formula of propellant calculated as

$$
\dot{m}_{\mathrm{g}}=a P_{\mathrm{g}}^{n} \rho_{\mathrm{p}} A_{\mathrm{p}}
$$

$A_{\mathrm{p}}$ should already be known when using this method. Therefore, it is suitable for a propellant with steady combustion area.
The third method is the characteristic velocity approach. The gas mass flow rate can be calculated as

$$
\dot{m}_{\mathrm{g}}=P_{\mathrm{g}} A_{\mathrm{g}} / C_{\mathrm{g}}^{*}
$$

The characteristic velocity of gas generator is specified by the propellant manufacturer. This method is suitable for propellant types with little deposition at the throat. The throat area remains the same during the experiment.

The experimental characteristic velocity of the SPDR $C_{\exp }^{*}$ is calculated as follows:

$$
C_{\exp }^{*}=a_{0} P_{\mathrm{c}}^{*} A_{\mathrm{t}} /\left(\dot{m}_{\mathrm{g}}+\dot{m}_{\mathrm{a}}\right)
$$

The total pressure is calculated based on the measured pressure at the end of the chamber, the Mach number in the chamber can be calculated as:

$$
q(M a)=a_{0} A_{\mathrm{t}} / A_{\mathrm{c}}
$$

$q(M a)$ is the flow function. The theoretical characteristic velocity, theoretical specific impulse and theoretical temperature of chamber are calculated by chemical equilibrium method. The experimental temperature of chamber can be calculated as

$$
T_{\mathrm{C}, \exp }=\left(C_{\mathrm{exp}}^{*} / C_{\mathrm{th}}^{*}\right)^{2} T_{\mathrm{C}, \mathrm{th}}
$$

As the temperature of the hot air is known, the combustion efficiency based on temperature rise can be calculated as

$$
\eta_{\mathrm{T}}=\left(T_{\mathrm{C}, \exp }-T_{\text {air }}\right) /\left(T_{\mathrm{C}, \mathrm{th}}-T_{\text {air }}\right)
$$

The predicted specific impulse of the test SPDR can be calculated as

$$
I_{\mathrm{a}, \text { pre }}=\left(F_{\mathrm{g}}-\dot{m}_{\mathrm{a}} v_{\mathrm{a}}+\left(p_{\mathrm{g}, \infty}-p_{\mathrm{h}, \infty}\right) A_{\mathrm{e}}\right) / \dot{m}_{\mathrm{g}}
$$

Therefore, the specific impulse efficiency can be calculated as follows:

$$
\eta_{\mathrm{I}}=I_{\mathrm{a}, \mathrm{pre}} / I_{\mathrm{th}}
$$

\section{Results and Discussion}

\subsection{Test results}

The effects of swirling flow, chamber length, propellant type and ER on combustion characteristics of the SPDR with a chin inlet are investigated experimentally and then discussed.

The test results are summarised in Table 2. It contains the measured pressure, measured thrust, the combustion efficiency based on temperature rise and specific impulse efficiency. Figure 5 shows the flame and plume of the boron-based propellant during fire test 04 . Bright yellow-white flame is observed at the exit of the nozzle, the plume and flame of the hydrocarbon propellant are similar.

The throat depositions of both propellant types after the experiments are shown in Fig. 6. Deposition exists at the gas generator throat for both propellant types. Deposition exists at the nozzle throat of the boron-based propellant, whereas deposition does not exist at the nozzle throat of the hydrocarbon propellant. Furthermore, the throat area undergoes little change when the boron-based propellant is 
Table 2. Geometries of the chamber.

\begin{tabular}{cllllllll}
\hline Test No. & 01 & 02 & \multicolumn{1}{c}{03} & \multicolumn{1}{c}{04} & \multicolumn{1}{c}{05} & \multicolumn{1}{c}{06} & \multicolumn{1}{c}{07} & \multicolumn{1}{c}{08} \\
\hline Str & I & I & II & II & II & II & II & II \\
Pro & A & A & A & A & A & A & B & B \\
ER & 0.41 & 0.61 & 0.46 & 0.58 & 0.27 & 0.44 & 0.67 & 0.40 \\
$L_{\mathrm{c}}$ & 730 & 730 & 730 & 730 & 730 & 580 & 580 & 580 \\
$P_{\mathrm{c}}$ & 0.55 & 0.58 & 0.55 & 0.56 & 0.46 & 0.56 & 0.53 & 0.51 \\
$F_{\mathrm{g}}$ & 1827 & 2179 & 1799 & 2047 & 2047 & 1810 & 1819 & 2349 \\
$\eta_{\mathrm{T}}$ & 0.88 & 0.88 & 0.95 & 0.93 & 0.41 & 0.85 & 0.78 & 0.61 \\
$\eta_{\mathrm{I}}$ & 0.80 & 0.87 & 0.80 & 0.85 & 0.50 & 0.69 & 0.68 & 0.55 \\
\hline
\end{tabular}

Str represents structure, Pro represents propellant, I represents the SPDR without swirling flow and II represents the SPDR with swirling flow. A represents the boron-based fuel-rich propellant, and $\mathrm{B}$ represents the hydrocarbon fuel-rich propellant. The units of $F_{\mathrm{g}}, P_{\mathrm{c}}, L_{\mathrm{c}}$ are N, MPa and mm.

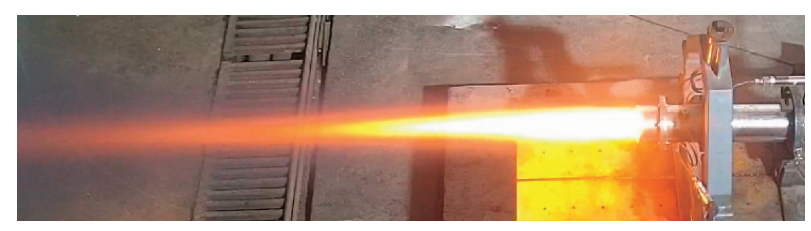

Fig. 5. Flame and plume during test 04 .

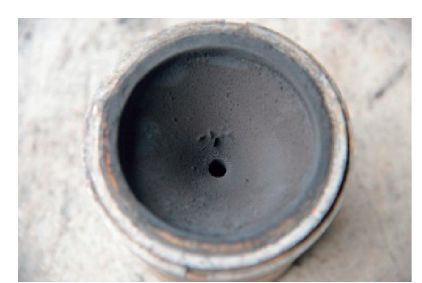

a

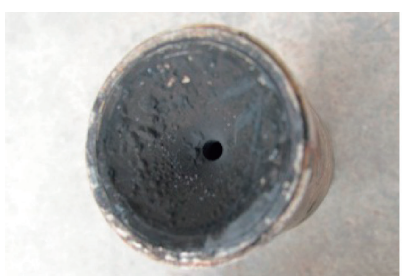

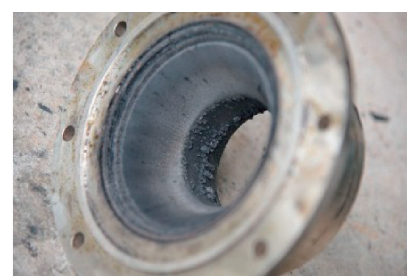

b

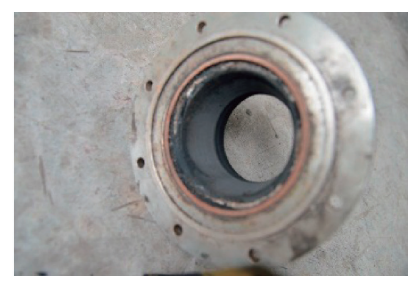

d
Fig. 6. Throat deposition of both propellants.

a. Deposition at gas generator throat of propellant A. b. Deposition at nozzle throat of propellant A. c. Deposition at gas generator throat of propellant B. d. Deposition at nozzle throat of propellant B.

used. By contrast, it remains almost the same when the hydrocarbon propellant is used due to the loose deposition of the hydrocarbon propellant.

Definition of the work time during experiments can be found in Fig. 7. Zero second represents that the piezoresistive pressure transducers start work, $t_{1}$ is the time when the air heater starts work, $t_{2}$ is the time when the gas generator ignites, $t_{3}$ is the time when the propellant starts steady combustion, $t_{4}$ is the time when the propellant ends combustion, $t_{5}$ is the time when the gas generator ends its work, and $t_{6}$ is the time when the air heater ends its work. The work time is defined from $t_{3}$ to $t_{4}$.

\subsection{Effect of swirling flow}

With tests 01 and 03, 02 and 04, effect of swirling flow on

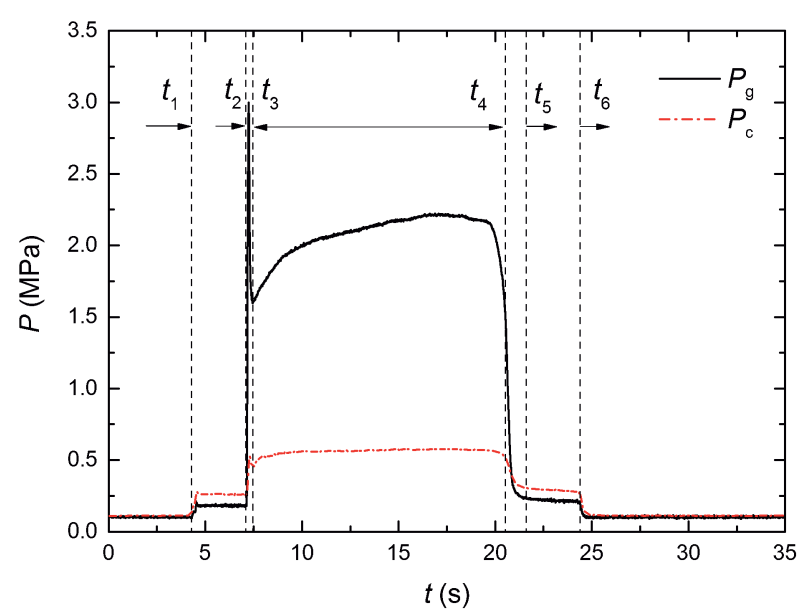

Fig. 7. Definition of work time during experiments.

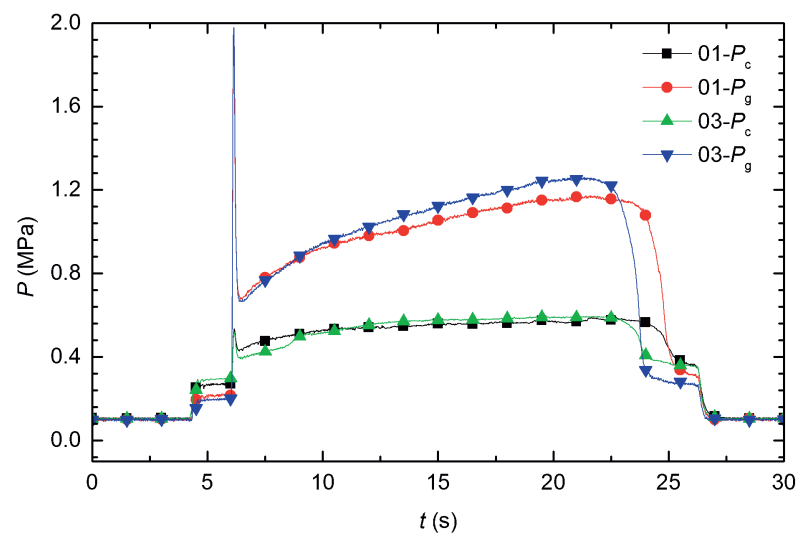

Fig. 8. Comparison of pressure evolutions between tests with and without swirling flow.

combustion performance could be discussed. As shown in Fig. 8, pressure of gas generator and chamber of these tests are almost the same, swirling flow is the main difference. Table 2 indicates that combustion efficiencies of the SPDR with swirling flow are higher than those of the SPDR without swirling flow when ERs are about 0.45 and 0.61 , respectively. This result implies that addition of swirling flow can improve combustion efficiency because of the enhancement of mixing between the ducted air and fuel-rich gas by swirling flow. This modification enhances combustion of the fuel-rich gas from gas generator, especially the condensation components, such as boron and carbon particles, which provide more than half of the total combustion energy. According to the previous work of the authors, ${ }^{25}$ ) oxygen concentration significantly affects the combustion time of boron and carbon particles. Therefore, mixing enhancement by swirling flow favours the combustion efficiencies of boron and carbon particles and could increase the combustion performance of SPDRs.

However, the specific impulse efficiencies are almost the same whether there is swirling flow or not. This result may be due to that addition of the swirler will cause stagnant pressure loss and thrust loss, although tests with swirling flow gain higher combustion efficiencies, the thrusts don't increase. Stagnant pressure loss can be decreases when the 


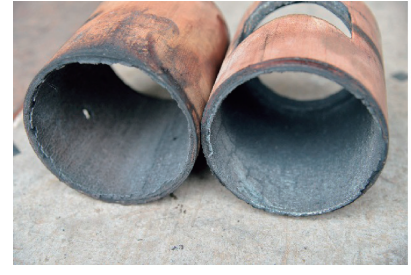

a

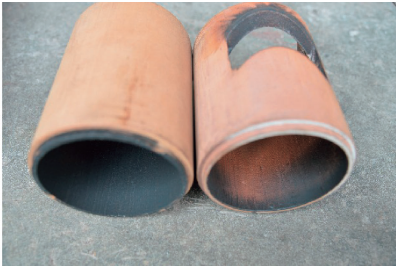

b
Fig. 9. Ablation of insulation after tests.

a. Ablation of insulation of test 02 . b. Ablation of insulation of test 04 .

swirler geometry is optimised.

Another advantage of the swirler is thermal protection ability as shown in Fig. 9. The ablation of insulation in test 02 is much heavier than that in test 04 when the theoretical temperatures of these two tests are similar, besides, the combustion efficiency of test 04 is higher. This result implies that the swirler could improve the thermal protection ability significantly. It is believed that the swirler generates an annular flow of the ducted air, which protects the wall from high temperature.

\subsection{Effect of chamber length}

The chamber length is important in SPDRs design. It should be long enough to ensure the sufficient combustion of fuel-rich gas and short enough to decrease the total mass of the SPDR.

The comparison of tests 03 and 06 show that combustion efficiency increases when length increases (Table 2 and Fig. 10) obviously. However, it can't continue increasing until $100 \%$ with the length increasing. For test 03 , the chamber length may be long enough to gain high combustion efficiency. Improvement may be achieved by organising and optimising the combustion process using different combustion technologies. In SPDRs, two issues should be regarded: the quick ignition and the rapid combustion of condensation particles. These issues depend on the mixing process directly. A poor mixing effect significantly increases the full combustion chamber length.

\subsection{Effect of propellant type}

The comparison of tests 06 and 08 and 07 show that the combustion efficiency in test 06 is higher than those in test 08 and test 07 . This result implies that the hydrocarbon propellant used in this study has lower combustion performance than the boron-based propellant. Considering the high specific impulse, we find that the boron-based propellant is the best choice for the SPDRs. The hydrocarbon propellant has little deposition and it may be a candidate for variable flow ducted rockets.

Figure 11 shows the ignition delay of the hydrocarbon propellant. The pressure of the gas generator builds up at $6 \mathrm{~s}$, but the pressure of the chamber does not change until $9.5 \mathrm{~s}$. This outcome implies that the fuel-rich gas of hydrocarbon propellant is not ignited at the first $3.5 \mathrm{~s}$. The plume in test 08 is black with no flame at first. After several seconds, it turns grey-black with a yellow flame. The authors suppose that the condensation phase (carbon) in fuel-rich gas generated by the hydrocarbon propellant cannot be ignited firstly, because ER is small, temperature of recirculation zone built

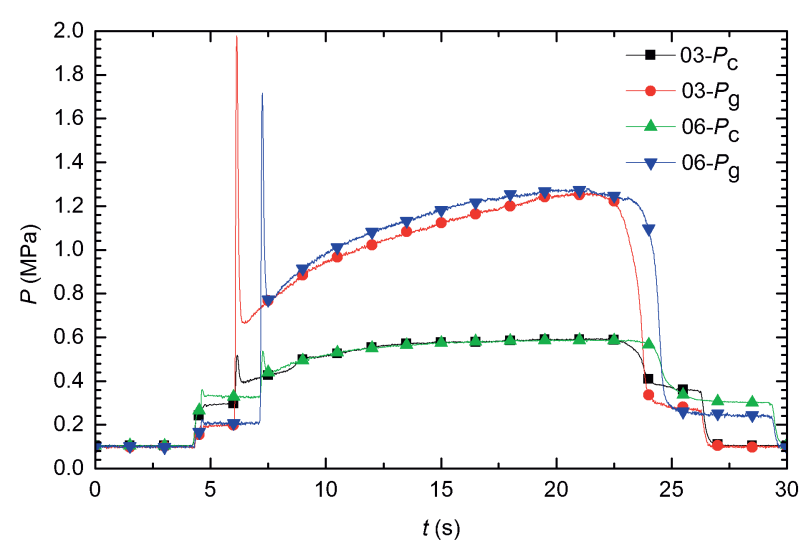

Fig. 10. Comparison of pressure evolutions between tests of different chamber lengths.

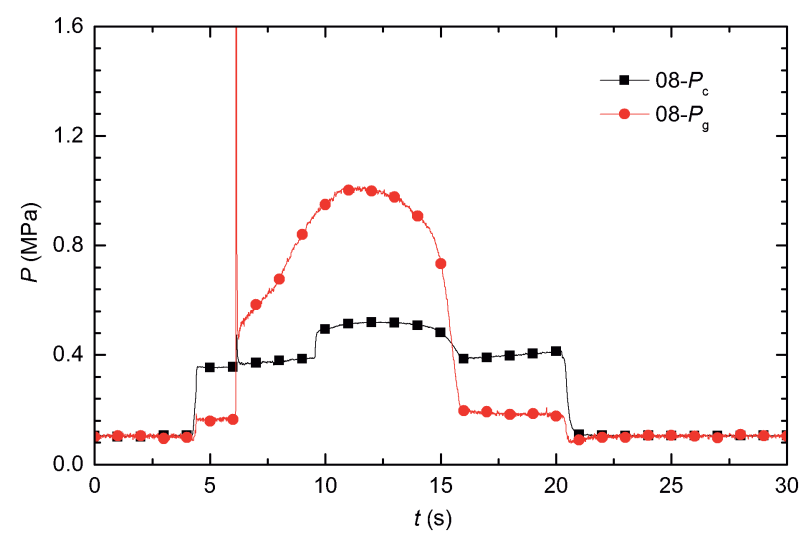

Fig. 11. Pressure evolutions of test 08 .

by the gas phase combustion is low, the condensation particles pass through and cannot be ignited. After several seconds, the pressure of gas generator increases much higher as shown in Fig. 11, it leads to the increasing of gas flow rate, temperature of recirculation zone turns higher, ignition of carbon particles could take place.

To validate this supposition, we conducted a test 07 with higher ER. The result is shown in Fig. 12. The ignition delay phenomenon still exists, but the ignition delay time decreases to less than $1 \mathrm{~s}$. This outcome indicates that the ignition delay phenomenon has a direct relation to ER and may be caused by the size of the high temperature zone.

\subsection{Effect of equivalence ratio}

The influence of ER on combustion characteristics of the SPDR is experimentally investigated. For boron-based propellant used in tests 01 and 02 and in tests 03 to 05 , one can find that the combustion efficiencies of the SPDR without swirling flow remain the same when ER decreases from 0.61 to 0.41 . By contrast, the combustion efficiencies of the SPDR with swirling flow increase first and then decrease as ER decreases from 0.58 to 0.27 . For hydrocarbon propellant, the combustion efficiencies decrease when ER decreases from 0.67 to 0.40 . This result indicates that the SPDR with a swirler achieves high combustion performance at high ER but low combustion performance at low ER. The swirler should be further optimized for a wide range of ER. 


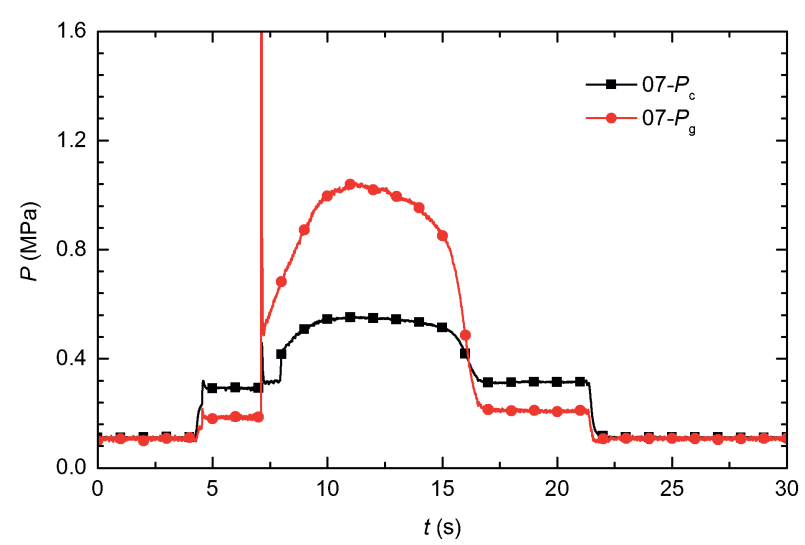

Fig. 12. Pressure evolutions of test 07.

\section{Conclusion}

In the current study, the combustion performance of a SPDR with a chin type inlet was investigated experimentally, a new configuration of SPDR with swirling flow was proposed and tested in this study, the influences of swirling flow, chamber length, propellant type and ER on the combustion characteristics were analyzed. We have arrived at the following conclusions.

- The swirler has a significant effect on combustion performance in the SPDR with a chin inlet. Combustion efficiency based on the temperature rise of the SPDR with swirling flow can reach $95 \%$, which is $7 \%$ higher than those for the SPDR without swirling flow. High combustion efficiency is achieved at test conditions when chamber length is adequately long.

- The combustion efficiencies of the hydrocarbon fuel-rich propellant are lower than the ones using the boron-based fuel-rich propellant in this study. An ignition delay problem is observed in the hydrocarbon propellant because the high temperature recirculation zone after the swirler is too small to ignite condensation particles. The ignition delay time decreases significantly when ER increases.

- When ER decreasing from 0.61 to 0.41 , combustion efficiencies of the SPDR without swirling flow remain the same. Whereas when ER decreasing from 0.67 to 0.40 , combustion efficiencies of the SPDR with swirling flow increase first and then decrease. The combustion efficiency decreases significantly when ER is 0.266 , that is to say, the swirler used in this study suffers from low combustion performance at a low ER.

- The swirler used in this study offers good thermal protection due to the annular flow of ducted air that protects the wall from high temperatures. There are little ablation of insulation when swirling flow exits.

\section{Acknowledgments}

This work was funded by the National Natural Science Foundation of China (No. 51406231 and No. 11572349).

\section{References}

1) Fry, R. S.: A Century of Ramjet Propulsion Technology Evolution, J. Propul. Power, 20 (2005), pp. 27-58.

2) Besser, H. L.: History of Ducted Rocket Development at BayernChemie, AIAA Paper 2008-5261, 2008.

3) Waltrup, P. J., White, M. E., and Zarlingo, F.: History of U.S. Navy Ramjet, Scramjet, and Mixed-Cycle Propulsion Development, J. Propul. Power, 18 (2002), pp. 14-27.

4) Hewitt, P. W.: Status of Ramjet Programs in the United States, AIAA Paper 2008-5265, 2008.

5) Davenas, A.: History of the Development of Solid Rocket Propellant in France, AIAA Paper 1993-1785, 1993.

6) Mitsuno, M., Kuwahara, T., and Kosaka, K.: Combustion of Metallized Propellants for Ducted Rockets, AIAA Paper 1987-1724, 1987.

7) Shin, K., Won, J., and Tak, H.: A Static Combustion Study on Fuel Rich Propellant for Ducted Rocket Gas Generator, AIAA Paper 2014-4045, 2014.

8) Li, H., Ao, W., and Wang, Y.: Effect of Carbon Dioxide on the Reactivity of the Oxidation of Boron Particles, Propellants Explos. Pyrotech., 39 (2014), pp. 617-623.

9) Liu, T., Luh, S., and Perng, H.: Effect of Boron Particle Surface Coating on Combustion of Solid Propellants for Ducted Rockets, Propellants Explos. Pyrotech., 16 (1991), pp. 156-166.

10) Vigot, C., Bardelle, L., and Nadaud, L.: Improvement of Boron Combustion in a Solid-fuel Ramrocket, AIAA Paper 1986-1590, 1986.

11) Schadow, K., Wilson, K., and Lee, M.: Enhancement of Mixing in Ducted Rockets with Elliptic Gas-generator Nozzles, AIAA Paper 1984-1260, 1984.

12) Brophy, C. M. and Hawk, C. W.: A Flow Visualization Facility for Ducted Rocket Engine Mixing Studies, AIAA Paper 1995-2934, 1995.

13) Brophy, C. M., Hawk, C. W., and Bush, J. M.: An Investigation of Four-inlet Ducted Rocket Engine Flameholding Characteristics, AIAA Paper 1997-2846, 1997.

14) Liou, T. M. and Wu, Y. Y.: LDV Measurements of the Flowfield in a Simulated Combustor with Axial and Side Inlets, Exp. Therm. Fluid Sci., 5 (1992), pp. 401-409.

15) Natan, B. and Gany, A.: Effects of Bypass Air on Boron Combustion in Solid Fuel Ramjets, J. Propul. Power, 9 (1993), pp. 155-157.

16) Kim, S. and Natan, B.: Inlet Geometry and Equivalence Ratio Effects on Combustion in a Ducted Rocket, J. Propul. Power, 31 (2015), pp. 619-631.

17) Natan, B. and Netzer, D. W.: Boron Carbide Combustion in Solid-fuel Ramjets Using Bypass Air. Part I: Experimental Investigation, Propellants Explos. Pyrotech., 21 (1996), pp. 289-294.

18) Xia, Z., Hu, J., and Fang, D.: Combustion Study of the Boron Particles in the Secondary Chamber of Ducted Rocket, AIAA Paper 2006-4445, 2006.

19) Stowe, R. A., Dubois, C., and Harris, P. G.: Performance Prediction of a Ducted Rocket Combustor Using a Simulated Solid Fuel, J. Propul. Power, 20 (2005), pp. 936-944.

20) Pein, R. and Vinnemeier, F.: Swirl and Fuel Composition Effects on Boron Combustion in Solid-fuel Ramjets, J. Propul. Power, 8 (1992), pp. 609-614.

21) Wu, P., Chen, M., and Chen, T.: Flowfields in a Side-inlet Ducted Ramrocket with/without Swirler, AIAA Paper 1995-2478, 1995.

22) Omer, M., Chen, X., and Zhou, C.: Experimental and Numerical Investigation on the Ignition and Combustion Stability in Solid Fuel Ramjet with Swirling Flow, Acta Astronautica, 137 (2017), pp. 157-167.

23) Webster, F. F.: Ramjet Development Testing-Which Way Is Right? J. Propul. Power, 5 (1989), pp. 565-576.

24) Wu, P., Chen, M., and Baurle, R. A.: Effects of Incorporating a Cone Swirler into a Side-Inlet Ducted Ramrocket, J. Propul. Power, 13 (1997), pp. 162-164.

25) Chen, B., Xia, Z., and Huang, L.: Ignition and Combustion Model of a Single Boron Particle, Fuel Process. Technol., 165 (2017), pp. 34-43.

Toru Shimada

Associate Editor 